\title{
Ionization and Dissociation of the Trifluoromethyl Halides by Electron Impact
}

\author{
Vernon H. Dibeler, Robert M. Reese, and Fred L. Mohler
}

\begin{abstract}
Relative abundances and appearance potentials are reported for positive and negative ions observed in $\mathrm{CF}_{4}, \mathrm{CF}_{3} \mathrm{Cl}, \mathrm{CF}_{3} \mathrm{Br}$, and $\mathrm{CF}_{3} \mathrm{I}$. The kinetic-energy distribution of positive ions is obtained by means of a "beam-deflection" technique. These data combined with that of recent thermochemical and spectroscopic studies permit a new calculation of the ionization potential of the $\mathrm{CF}_{3}$ radical of $9.3 \pm 0.2$ electron volts, as well as estimates of fluorocarbon bond-dissociation energies. The energetics of probable dissociation processes are discussed.
\end{abstract}

\section{Introduction}

There is considerable qualitative evidence of the remarkable thermal and chemical stability of fluorocarbons and many of their derivatives [1]. ${ }^{1}$ However, quantitative evaluation is limited almost entirely to measurements of the heats of formation of a few of the simplest members of the aliphatic series and their derivatives $[2,3,4]$. Luft [5] gives estimates of $\mathrm{C}-\mathrm{F}$ and $\mathrm{C}-\mathrm{C}$ bond-dissociation energies in a brief review of recently published thermochemical data for a number of simple organic fluorine compounds.

Values of the ionization and appearance potentials of ions from $\mathrm{CF}_{4}$ and some other trifluoromethanes appear in scattered reports $[6,7,8,9]$. One attempt to measure fluorocarbon bond-dissociation energies by electron impact necessitated an indirect measure of the ionization potential of the $\mathrm{CF}_{3}$ radical and yielded the value, $I\left(\mathrm{CF}_{3}\right)=8.9 \mathrm{ev}[10]$. This value combined with observed appearance potentials of the $\mathrm{CF}_{3}{ }^{+}$ions from $\mathrm{CF}_{4}[5]$ and $\mathrm{C}_{2} \mathrm{~F}_{6}[9]$ results in the unexpectedly high values of 164 and 124 kcal, respectively, for the dissociation energies of the first $\mathrm{C}-\mathrm{F}$ bond in $\mathrm{CF}_{4}$ and the $\mathrm{C}-\mathrm{C}$ bond in $\mathrm{C}_{2} \mathrm{~F}_{6}$. Although both values are considered upper bounds, there is evidence [5] that the true $\mathrm{CF}_{3}-\mathrm{CF}_{3}$ bonddissociation energy is "smaller, but not much smaller" than 124 kcal.

Farmer, Henderson, Lossing, and Marsden [11] report the successful production of $\mathrm{CF}_{3}$ radicals in the mass spectrometer by means of the thermal decomposition of hexafluoroazomethane, thus permitting a direct measure of the ionization potential, $I\left(\mathrm{CF}_{3}\right)=10.10 \pm 0.05 \mathrm{ev}$. Although this value leads to a heat of formation of the $\mathrm{CF}_{3}$ radical in agreement with that determined by Rabinovitch and Reed [12], Farmer et al., also report that the application of this value to observed appearance potentials of the $\mathrm{CF}_{3}^{+}$ions from $\mathrm{CF}_{3} \mathrm{Cl}, \mathrm{CF}_{3} \mathrm{Br}$, and $\mathrm{CF}_{3} \mathrm{I}$ results in values for the $\mathrm{CF}_{3}-\mathrm{X}$ bond-dissociation energies that are evidently too low by an amount approaching $1 \mathrm{ev}$.

\footnotetext{
1 Figures in brackets indicate the literature references at the end of this paper.
}

The present paper reports the experimental results of a broad study of the ionization and dissociation of $\mathrm{CF}_{4}, \mathrm{CF}_{3} \mathrm{Cl}, \mathrm{CF}_{3} \mathrm{Br}$, and $\mathrm{CF}_{3} \mathrm{I}$ with the primary intent of resolving the apparent discrepancy between the direct and indirect measurement of $I\left(\mathrm{CF}_{3}\right)$. Dissociation processes for all of the principal ions of the trifluorohalomethanes are reported, and the study includes observations on negative ions and ions formed with excess kinetic energy.

\section{Experimental Details}

Appearance potential data for both positive and negative ions were obtained by means of a $180^{\circ}$. mass spectrometer, using instrumental arrangements and methods of evaluating threshold potentials previously described in detail [13]. Relative abundances of positive ions were measured under conventional conditions, using $70-\mathrm{v}$ electrons. The spectroscopic ionization potential of argon (simultaneously introduced with the sample gas) was used to calibrate the ionizing voltage scale for positive ions. The appearance potential of the $\mathrm{O}^{-}$ion of $\mathrm{CO}$ was measured as a check on the voltage scale for negative ions. The small correction required to make the observed appearance potential (9.8 $\pm 0.2 \mathrm{v}$ ) conform with that reported by Hagstrum $(9.6 \pm 0.2 \mathrm{v})[14]$ was assumed constant over the entire voltage scale. An approximate correction was made for the difference in the efficiency of collecting positive and negative ions, using the method employed by Marriott and Craggs [8]. The $\mathrm{O}^{-} / \mathrm{O}^{+}$ratio measured with $35-\mathrm{v}$ electrons indicated a negative-ion collection efficiency for the present instrument of about 31 percent compared with 50 percent reported by Marriott and Craggs.

A preliminary search was made for positive ions formed with excess kinetic energy by recording the mass spectrum with a low ion-accelerating potential [13]. Kinetic energy of negative ions was not investigated. A more detailed study was made, using the beam-deflection method described by Berry [15]. In the latter method, deflecting electrodes mounted in the analyzer region are used to move the ion beam parallel to the length of the collector slit. By proper shortening of the length of 
the slits at the entrance and exit to the analyzer region, and by adjustment of the deflecting electrode potentials, small portions of the original ion beam are recorded, and a plot of the ion current versus deflecting voltage shows the shape of one component of the initial velocity distribution of the ions. Berry finds that the relation between the velocity scale and various other factors is given by

$$
U=A P(e / m V)^{1 / 2},
$$

where $A$ is a constant that is characteristic of the instrument, $P$ is the deflecting potential in volts, $e$ is the particle charge in electrostatic units, $m$ is the particle mass in grams, and $V$ is the ion-accelerating potential in volts. The constant $A$ is best evaluated by empirical means, and the Maxwellian distributions obtained for the molecule ions of $\mathrm{CO}, \mathrm{CF}_{3} \mathrm{Br}$, and $\mathrm{CF}_{3} \mathrm{I}$ were used for this purpose. As $A$ varied somewhat with the ion-accelerating potential (probably for reasons suggested by Berry) all measurements of kinetic-energy distributions were made at the same ion-accelerating voltage of $1,000 \mathrm{v}$.

The trifluoromethyl chloride, bromide, and iodide were made from the silver salt of trifluoroacetic acid and the appropriate halogen [1]. Quantities sufficient for mass spectrometric studies were easily made in sealed tubes containing a slight excess of the silver trifluoroacetate. Simple distillation through $\mathrm{KOH}$ pellets was sufficient to separate the desired products. The $\mathrm{CF}_{4}$ was obtained from the Minnesota Mining \& Manufacturing Co. No fluorocarbon impurities were detected in any of the samples, and it is estimated that they are less than 0.1 mole percent.

\section{Results}

\subsection{Determination of Appearance Potentials}

Figure 1 shows three determinations of the initial portions of ionization-efficiency curves for the $\mathrm{CF}_{3}^{+}$ ion of $\mathrm{CF}_{3} \mathrm{Br}$ and the $\mathrm{A}^{+}$ion of the calibration gas, argon, plotted on a semilog scale with the electronenergy scale shifted to permit display of the three sets of data. As these curves are very nearly straight and parallel, the voltage interval between the $\mathrm{CF}_{3}^{+}$ ion curve and the associated calibration curve is subtracted from the spectroscopic ionization potential of argon (15.76 ev) [16] to obtain the appearance potential of the $\mathrm{CF}_{3}^{+}$ion. Similar curves were obtained for the $\mathrm{CF}_{3}^{+}$ions of the other trifluoromethyl halides and for the molecule ions of $\mathrm{CF}_{3} \mathrm{Br}$ and $\mathrm{CF}_{3} \mathrm{I}$. Ionization-efficiency curves for other positive fragment ions showed considerable deviation from straight lines and parallelism with respect to the calibration curve. In these cases, the voltage interval is measured at a point on the curves extrapolated to an ion current equal to a tenth of a scale division on the record. This results in a larger uncertainty in the evaluation of the respective appearance potentials.

The ionization-efficiency curves of the negative ions are illustrated in figure 2 , which shows the curves

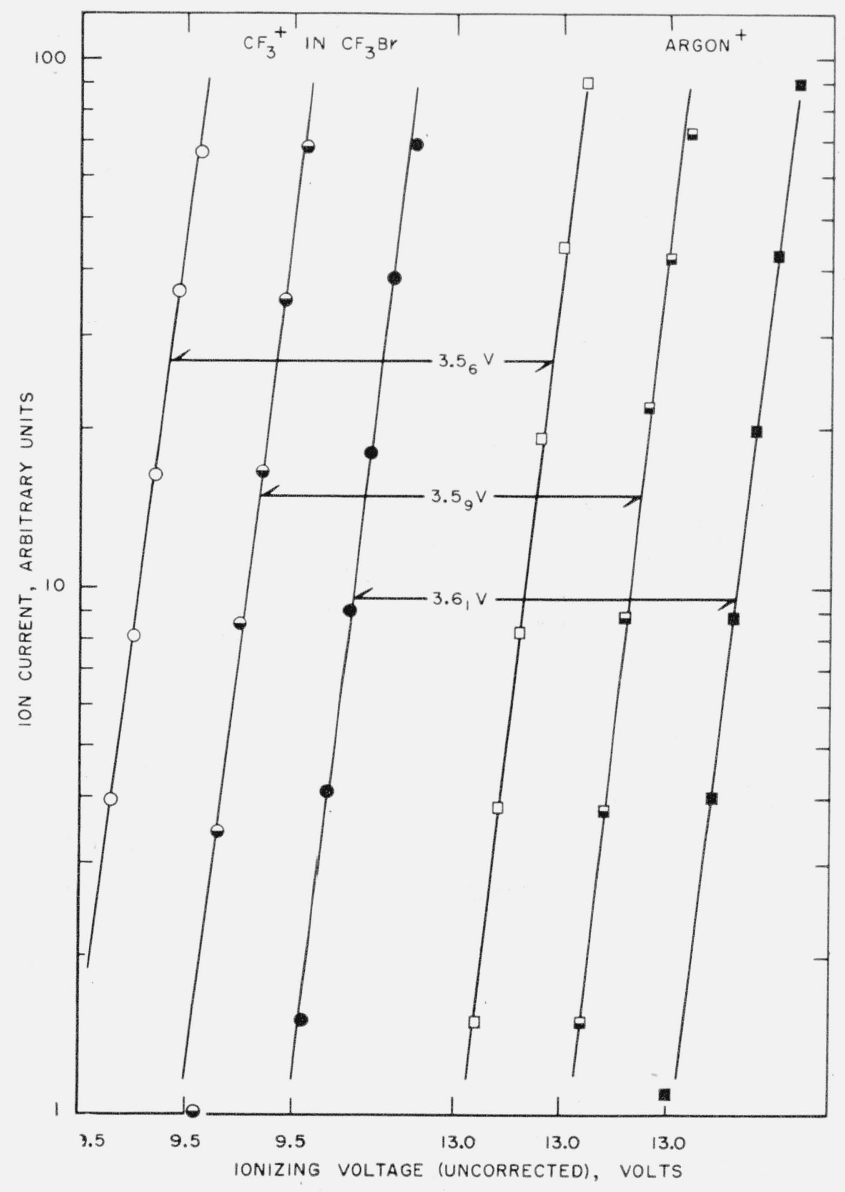

FIguRe 1. Repeat determinations of initial portions of the ionization-efficiency curves for the $\mathrm{CF}_{s}^{+}$ion of $\mathrm{CF}_{3} \mathrm{Br}$ and the calibration gas, argon, plotted on a semilog scale.

The electron energy scale is uncorrected and shifted for each curve. The indicated voltage intervals subtracted from the ionization potential of argon give the appearance potentials for the $\mathrm{CF}_{3}$ ion.

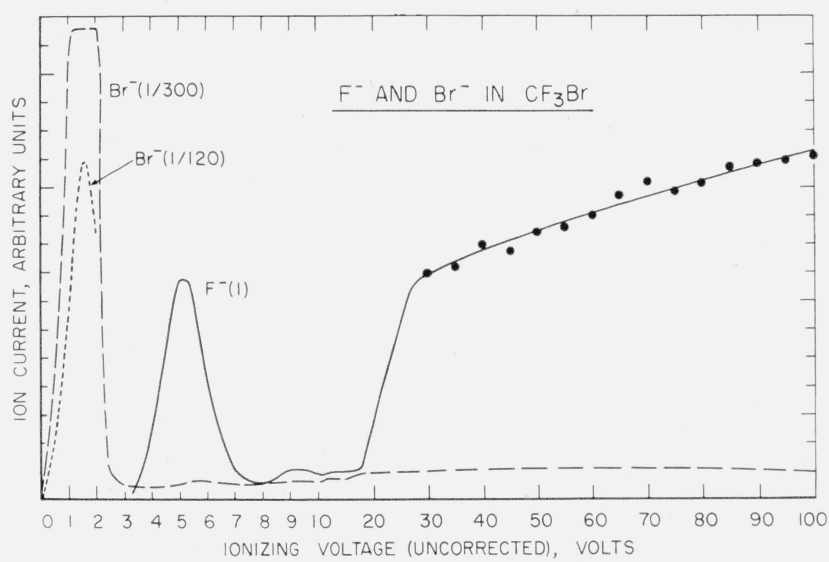

Figure 2. Ionization-efficiency curves for the $\mathrm{Br}^{-}$and $\mathrm{F}^{-}$ ions of $\mathrm{CF}_{3} \mathrm{Br}$ plotted on a linear scale.

The sensitivity for the two $\mathrm{Br}^{-}$curves is $1 / 120$ and $1 / 300$ of that for the $\mathrm{F}^{-}$ion. The voltage scale is uncorrected. 
for $\mathrm{Br}^{-}$and $\mathrm{F}^{-}$ions from $\mathrm{CF}_{3} \mathrm{Br}$. From the higher sensitivity data, the $\mathrm{Br}^{-}$ion is apparently formed by a dissociative attachment process with an appearance potential very near to zero volts. There is no evidence for other dissociative ionization processes for energies up to $100 \mathrm{v}$. Hickam and Fox [17] have shown that for monoenergetic electrons, attachment processes occur over a very narrow range (less than $0.1 \mathrm{v})$ of electron energies. Therefore, the width of the peaks shown in figure 2 is probably the result of energy spread in the electron beam. Alinearity in the amplifier occurs near the top of the high-sensitivity peak and results in the flat appearance.

The $\mathrm{F}^{-}$ion is formed both by dissociative attachment and by an ion-pair process. There is some evidence for at least one other attachment process of very low probability. The appearance potential of the ion-pair process is relatively simple to evaluate. However, that of the attachment process is subject to somewhat greater uncertainty because of the probable change in calibration of the energy scale within the first few volts. $\mathrm{F}^{-}$ions are formed by dissociative attachment alone in the $\mathrm{CF}_{4}$ and $\mathrm{CF}_{3} \mathrm{Cl}$ compounds. They are formed both by attachment and by an ion pair process in the bromide and iodide compounds. The other halogen negative ions are formed by attachment only. $\mathrm{A} \mathrm{CF}_{3}^{-}$ion (by attachment) is observed in $\mathrm{CF}_{4}$.

\subsection{Measurement of Kinetic Energy}

Observations on ions formed with excess kinetic energy were made for all of the trifluoromethyl halides by measuring the distribution of ion current in a direction parallel to the exit slit length. Figure 3 illustrates the ion-current distribution curves obtained for the molecule ions of $\mathrm{CF}_{3} \mathrm{Br}$ and $\mathrm{CF}_{3} \mathrm{I}$ and the $\mathrm{CF}_{3}^{+}$and $\mathrm{CF}_{2}^{+}$ions of all of the trifluoromethyl compounds plotted on a small scale to conserve space. The abscissas are calibrated directly in electron volts of kinetic energy, and the ordinates are arbitrary units of ion current. Larger-scale plots including more experimental points are used for the quantitative estimates of the kinetic energy.

As expected, the molecule ions show a narrow distribution about the origin, with a very sharp maximum at the approximate geometrical and electrical center of a cross section of the ion beam. The $\mathrm{CF}_{3}^{+}$ ions of the chloride, bromide, and iodide molecules display similar distributions, although somewhat wider at the base. Few, if any, of these ions are formed with excess kinetic energy. The $\mathrm{CF}_{3}^{+}$ion of $\mathrm{CF}_{4}$, however, exhibits definite maxima on either side of the beam center, indicating that most of these ions are formed with about $0.1-\mathrm{ev}$ excess kinetic energy but that the distribution in this range is again very narrow.

The $\mathrm{CF}_{2}^{+}$ions show definite breaks and considerable broadening at the base. From $\mathrm{CF}_{4}$ to $\mathrm{CF}_{3} \mathrm{I}$, the break appears at increasing values of the kinetic energy as would follow from the conservation of momentum, assuming nearly equal total kinetic energy in each case. The $\mathrm{CF}_{2} \mathrm{X}^{+}$energy-distribution curves (not shown in the figure) are quite similar to

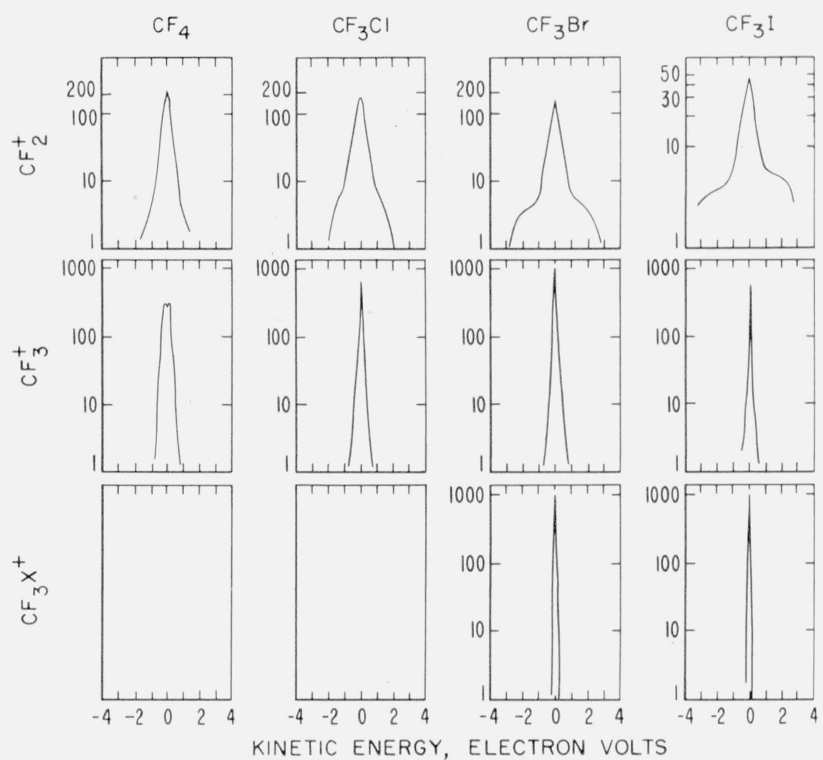

FIGURE 3. Ion current distribution in the ion beam for selected ions of the trifluoromethyl halides for $70-v$ electrons.

Kinetic energy is plotted for each abscissa, and ion current in arbitrary units is plotted for each ordinate.

the molecule-ion curves and give no indication of excess kinetic energy. All other fragment-ion curves, however, exhibit broad distributions or definite breaks.

Table 1 summarizes the complete experimental data obtained for the trifluoromethyl halides. Column 1 lists the ions observed. Column 2 gives the abundances of positive ions relative to the most abundant positive ion for $70-\mathrm{v}$ electrons. The abundances of the negative ions are measured at maximum abundance and are corrected for the observed difference in the efficiency of collecting positive and negative ions. Column 3 gives the mean of at least three measurements of the appearance potential of each positive ion with the uncertainty estimated from the experimental data.

\section{Discussion}

\subsection{Molecular Ionization Potentials}

Spectroscopic ionization potentials of the trifluoromethyl halides have not been published. A previous measurement of the $\mathrm{CF}_{3} \mathrm{Cl}$ molecule by electron impact is quoted in column 5 of table 1 . The agreement is just within the total estimated uncertainties and is satisfactory, considering the low relative abundance of this ion. No breaks in the ionizationefficiency curves corresponding to the ${ }^{2} \mathrm{E}_{3 / 2}$ and ${ }^{2} \mathrm{E}_{1 / 2}$ spin orbital components of the parent-ion ground states were observed. This is not surprising, however, as detection of doublets in methyl bromide and iodide by electron impact apparently requires the use of nearly monoenergetic electron beams [18]. 
TABLE 1. Summary of relative-abundance, appearance-potential, and kinetic-energy measurements for the trifluoromethyl halides

\begin{tabular}{|c|c|c|c|c|}
\hline Ion & $\begin{array}{c}\text { Relative } \\
\text { abundance }\end{array}$ & $\begin{array}{l}\text { Appearance } \\
\text { potential }\end{array}$ & Remarks & Comparison values \\
\hline \multicolumn{5}{|c|}{$\mathrm{CF}_{4}$} \\
\hline $\mathrm{CF}_{4}^{+}$ & $\begin{array}{c}\% \\
<0.01\end{array}$ & $e v$ & & \\
\hline $\mathrm{CF}_{3}^{+}$ & 100.0 & $16.0 \pm 0.2$ & Mast ions formed with kinetic energy $\approx 0.1 \mathrm{ev}$ & $15.44 \pm 0.05[7], 15.9 \pm 0.2[6]$. \\
\hline $\mathrm{CF}_{2}^{+}$ & 14.5 & $20.3 \pm 0.5$ & Thermal ions and ions with kinetic energy $\approx 0.8 \mathrm{ev}$ & $22.4 \pm 0.2[7], 21.8 \pm 0.3[6]$ \\
\hline $\begin{array}{l}\mathrm{CF}^{+} \\
\mathrm{C}^{+} \\
\mathrm{F}^{+} \\
\mathrm{F}^{-}\end{array}$ & $\begin{array}{l}3.7 \\
9.4 \\
5.7 \\
0.8\end{array}$ & $\begin{array}{l}22.6 \pm 0.5 \\
31.5 \pm 0.5 \\
36 . \pm 1 \\
4.5 \pm 0.3\end{array}$ & $\begin{array}{l}\text { Broad kinetic-energy distribution } \\
\text { Dissociative attachment, maximum abundance at } 8 \mathrm{v}\end{array}$ & $\begin{array}{l}27.2 \pm 0.5[7], 29.8 \pm 0.3[6] \\
27.5 \pm 1[6] . \\
39.8 \pm 0.8[7], 35.5 \pm 1[6]\end{array}$ \\
\hline $\mathrm{CF}_{3}^{-}$ & .09 & $4.9 \pm 0.3$ & do & \\
\hline \multicolumn{5}{|c|}{$\mathrm{CF}_{3} \mathrm{Cl}$} \\
\hline $\mathrm{CF}_{3} \mathrm{Cl}^{+}$ & 0.5 & $13 \pm 1$ & & $12.8 \pm 0.2[7]$. \\
\hline $\mathrm{CF}_{3}^{+}$ & 100.0 & $12.7 \pm 0.2$ & Thermal-energy ions only .... & $12.95 \pm 0.05[7], 13.0 \pm 0.06[11]$ \\
\hline $\mathrm{CF}_{2} \mathrm{Cl}^{+}$ & 13.3 & $15.0 \pm 0.4$ & - do & $15.5 \pm 0.2[7]$ \\
\hline $\mathrm{CF}_{2}^{+}$ & 2.4 & $20 \quad \pm 1$ & Thermal ions and ions with kinetic energy $\approx 1 \mathrm{ev}$ & $21.0 \pm 0.2[7]$ \\
\hline $\begin{array}{ll}\mathrm{CF}^{+} \\
\mathrm{C}^{+}\end{array}$ & $\begin{array}{l}4.4 \\
3.2\end{array}$ & ${ }_{31}^{22.6} \pm 0.5$ & Broad kinetic-energy distribution & $25.0 \pm 0.2[7]$ \\
\hline $\begin{array}{l}\mathrm{Cl}^{+}+ \\
\mathrm{C} 1^{+}\end{array}$ & $\begin{array}{l}3.2 \\
1.1 \\
6.5\end{array}$ & $\begin{array}{lll}31 & \pm 1 \\
31 & \pm 1 \\
21 & \pm 1\end{array}$ & Thermal ions and ions with kinetic energy $\approx 1 \mathrm{ev}$ & $\begin{array}{l}35.0 \pm 0.5[7] \\
21.0 \pm 0.2[7]\end{array}$ \\
\hline $\mathrm{F}^{-}$ & 0.2 & $\begin{array}{l}3.8 \pm 0.3 \\
20\end{array}$ & $\begin{array}{l}\text { Dissociative attachment, maximum abundance at } 5.5 \mathrm{v} \\
\text { Ion-pair process }\end{array}$ & \\
\hline $\mathrm{Cl}^{-}$ & .1 & $\approx 0 \quad 4.7 \pm 0.3$ & $\begin{array}{l}\text { Dissociative attachment, maximum abundance at } 2.7 \mathrm{v} \\
\text { Dissociative attachment, maximum abundance at } 6.4 \mathrm{v}\end{array}$ & \\
\hline \multicolumn{5}{|c|}{$\mathrm{CF}_{3} \mathrm{Br}$} \\
\hline $\mathrm{CF}_{3} \mathrm{Br}^{+}$ & 11.2 & $12.3 \pm 0.3$ & & \\
\hline $\mathrm{CF}_{3}^{+}$ & 100.0 & $12.2 \pm 0.2$ & Thermal-energy ions only & $12.1[11]$. \\
\hline $\mathrm{CF}_{2} \mathrm{Br}^{+}$ & 8.9 & $15.0 \pm 0.7$ & do & 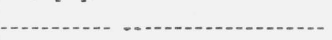 \\
\hline $\mathrm{CF}_{2}^{+}$ & 5.8 & $19.5 \pm 0.5$ & Thermal ions and ions with kinetic energy $\approx 1.2 \mathrm{ev}$ & \\
\hline $\mathrm{CF}^{+}$ & 4.3 & $22.9 \pm 0.5$ & Broad kinetic-energy distribution & $-\ldots$ \\
\hline $\begin{array}{l}\mathrm{C}^{+} \\
\mathrm{F}^{+}\end{array}$ & $\begin{array}{l}1.8 \\
0.5\end{array}$ & $\begin{array}{ll}33 & \pm 1 \\
29 & \pm 1\end{array}$ & do & - \\
\hline $\mathrm{Br}^{+}$ & 5.8 & $17.6 \pm 1$ & Thermal ions and ions with kinetic energy $\approx 1 \mathrm{ev}$ & \\
\hline $\mathrm{F}^{-}$ & 0.06 & $\left\{\begin{aligned} 3.5 \pm 0.3 \\
17.9 \pm 1\end{aligned}\right.$ & $\begin{array}{l}\text { Dissociative attachment, maximum abundance at } 5.2 \mathrm{v}_{-} \\
\text {Ion-pair process }\end{array}$ & \\
\hline $\mathrm{Br}^{-}$ & 11.3 & $\approx 0$ & Dissociative attachment, maximum abundance at $1.5 \mathrm{v}$ & $\approx 0[8]$. \\
\hline \multicolumn{5}{|c|}{$\mathrm{CF}_{3} \mathrm{I}$} \\
\hline $\mathrm{CF}_{3} \mathrm{I}^{+}$ & 68.5 & $10.0 \pm 0.3$ & & \\
\hline $\mathrm{CF}_{3}^{+}$ & 71.0 & $11.4 \pm 0.4$ & Thermal ions only & \\
\hline $\mathrm{CF}_{2} \mathrm{I}^{+}$ & 100.0 & $15.3 \pm 0.3$ & do & - \\
\hline $\mathrm{CF}_{2}^{+}$ & 2.6 & $18.5 \pm 0.6$ & Thermal ions and ions with kinetic energy $\approx 1.2 \mathrm{ev}$ & -...... \\
\hline $\mathrm{CF}^{+}$ & 6.0 & $20.7 \pm 1$ & Broad kinetic-energy distribution & - \\
\hline $\begin{array}{l}\mathrm{C}^{+} \\
\mathrm{F}^{+}\end{array}$ & $\begin{array}{l}2.4 \\
0.6\end{array}$ & $\begin{array}{l}32.6 \pm 1 \\
33\end{array}$ & & \\
\hline $\mathrm{I}^{++}$ & $\begin{aligned} 0.0 \\
33.5\end{aligned}$ & 13. $6 \pm 0.5$ & Thermal ions and ions with kinetic energy $\approx 0.4 \mathrm{ev}_{-}-\cdots$ & $12.9 \pm 0.15[11]$ \\
\hline $\mathrm{F}^{-}$ & $\approx 0.1$ & $\left\{\begin{aligned} 3.6 \pm 0.3 & \\
14 & \pm 1\end{aligned}\right.$ & $\begin{array}{l}\text { Dissociative attachment, maximum abundance at } 5.6 \mathrm{v}_{-} \ldots-. . \\
\text { Jon-pair process }\end{array}$ & \\
\hline $\mathrm{I}^{-}$ & $\approx 1$ & $\approx 0 \quad \pm 1$ & Dissociative attachment, maximum abundance at $1.8 \mathrm{v}_{-}$ & \\
\hline
\end{tabular}

A molecule ion is not observed in $\mathrm{CF}_{4}$. It is estimated that the relative abundance for $70-\mathrm{V}$ electrons is less than 0.01 percent of the $\mathrm{CF}_{3}^{+}$ion.

\subsection{Ionization Potential of the $\mathrm{CF}_{3}$ Radical}

Column 3 of table 1 gives appearance potentials of $\mathrm{CF}_{3}$ radicals of the four molecules, and column 5 includes comparison values from published research for three of the molecules. In several cases there are discrepancies slightly greater than the estimated experimental errors. Except in the case of $\mathrm{CF}_{4}$ these ions have no excess kinetic energy. An observed kinetic energy of roughly $0.1 \mathrm{ev}$ for $\mathrm{CF}_{3}^{+}$of $\mathrm{CF}_{4}$ would indicate a total kinetic energy of about $0.5 \mathrm{ev}$ for the two fragments.
Direct thermochemical measurements of the $\mathrm{CF}_{3}$ $\mathrm{Br}$ and the $\mathrm{CF}_{3}-\mathrm{Cl}$ bond-dissociation energies have been reported. Sehon and Szwarc [19], using the "toluene-carrier" technique, find $64.5 \mathrm{kcal}(2.80 \mathrm{ev})$ for $D\left(\mathrm{CF}_{3}-\mathrm{Br}\right)$, and Rabinovitch and Reed [12] report $79.5 \mathrm{kcal}(3.45 \mathrm{ev})$ for $D\left(\mathrm{CF}_{3}-\mathrm{Cl}\right)$ from sodium diffusion flame experiments. As the $\mathrm{CF}_{3}^{+}$ ions of $\mathrm{CF}_{3} \mathrm{Br}$ and $\mathrm{CF}_{3} \mathrm{Cl}$ are formed with thermal energies only, subtracting the $\mathrm{CF}_{3}-\mathrm{X}$ bond-dissociation energies from the appearance potentials of the respective $\mathrm{CF}_{3}^{+}$ions yields $9.4 \pm 0.2 \mathrm{ev}$ and 9.2 $\pm 0.2 \mathrm{ev}$ for the ionization potential of the $\mathrm{CF}_{3}$ radical. An average value of $I\left(\mathrm{CF}_{3}\right)=9.3 \pm 0.2 \mathrm{ev}$ is obtained from these two compounds.

This is intermediate between the two conflicting values of $8.9 \mathrm{ev}$ [10] and $10.1 \mathrm{ev}$ [11] referred to in 
the introduction. The value of $9.3 \mathrm{ev}$ could be reconciled with the measured appearance potentials of $\mathrm{CF}_{3}^{+}$and $\mathrm{CH}_{3}^{+}$of methyl fluoroform [10] if a total kinetic energy of $0.4 \mathrm{ev}$ is associated with either ionization process. An experiment using the beamdeflection method gave no evidence of excess kinetic energy of either ion at low ionizing voltages. ${ }^{2}$ However, the possibility of vibrational excitation in the $\mathrm{CH}_{3}^{+}$ion production should not be neglected. This might result from dissociation from the first excited state of the molecule ion corresponding to ionization from an orbital localized on the $\mathrm{CH}_{3}$ group.

Recent estimates of the dissociation energy $D\left(\mathrm{CF}_{3}-\mathrm{F}\right)$ range from $116 \mathrm{kcal}$ [12] to $195 \mathrm{kcal}$ [21]. Luft [5], on consideration of recently published enthalpies of formation and other thermochemical data, derives a value of $138 \pm 4$ kcal. Calculation of this bond energy from the appearance potential of $\mathrm{CF}_{3}^{+}$from $\mathrm{CF}_{4}, 16.0 \mathrm{ev}$, using $9.3 \mathrm{ev}$ for the ionization potential of $\mathrm{CF}_{3}$ and $0.5 \mathrm{ev}$ for the kinetic energy of the products gives $6.2 \pm 0.2 \mathrm{ev}$ or $143 \pm 5$ kcal, in good agreement with Luft's value.

The appearance potential of $\mathrm{CF}_{3}^{+}$from hexafluoroethane is $14.3 \mathrm{ev}[10]$. Using the above value of $I\left(\mathrm{CF}_{3}\right)$ gives a value of $D\left(\mathrm{CF}_{3}-\mathrm{CF}_{3}\right)=5.0 \pm 0.2$ $\mathrm{ev}$, or $115 \pm 5 \mathrm{kcal}$. This again is in good agreement with Luft's estimated value of $107 \pm 8$ kcal for this bond energy [5].

There are no direct measurements of $D\left(\mathrm{CF}_{3}-\mathrm{I}\right)$. The appearance potential of $\mathrm{CF}_{3}^{+}$from $\mathrm{CF}_{3} \mathrm{I}, 11.4$ $\mathrm{ev}$, and the value $9.3 \mathrm{ev}$ for $I\left(\mathrm{CF}_{3}\right)$ gives $D\left(\mathrm{CF}_{3}-\mathrm{I}\right)$ equal to $2.1 \pm 0.2 \mathrm{ev}$, or $48.5 \pm 5 \mathrm{kcal}$. The differences in the bond energies, $D\left(\mathrm{CH}_{3}-\mathrm{Cl}\right)-D\left(\mathrm{CF}_{3}-\right.$ $\mathrm{Cl})=1.7$ keal and $D\left(\mathrm{CH}_{3}-\mathrm{Br}\right)-D\left(\mathrm{CF}_{3}-\mathrm{Br}\right)=3$ kcal suggest that the difference in the values $D\left(\mathrm{CH}_{3}-\mathrm{I}\right)-D\left(\mathrm{CF}_{3}-\mathrm{I}\right)$ will be 4 or 5 kcal. The bond energy $D\left(\mathrm{CH}_{3}-\mathrm{I}\right)$ is $55 \mathrm{kcal}$ [22]. Thus the expected value for $D\left(\mathrm{CF}_{3}-\mathrm{I}\right)$ is about $50 \mathrm{kcal}$. The agreement is again very satisfactory.

It is concluded that a value of $9.3 \pm 0.2 \mathrm{ev}$ for the ionization potential of $\mathrm{CF}_{3}$ leads to consistent values for bond-dissociation energies of all four trifluoromethyl halides, as well as for the $\mathrm{C}-\mathrm{C}$ bond of perfluoroethane, and the only outstanding discrepancy is the above noted case of the $\mathrm{C}-\mathrm{C}$ bond of methyl fluoroform.

\subsection{Formation of Atom Ions}

Combining the heat of formation of $\mathrm{CF}_{4}(-220.4$ kcal) [4], the dissociation energy of $\mathrm{F}_{2}$ (38 kcal) [23] and the sublimation energy of carbon $(170 \mathrm{kcal})$ gives $-466 \mathrm{kcal}(20.2 \mathrm{ev})$ as the energy required for the reaction

$$
\mathrm{CF}_{4} \rightarrow \mathrm{C}(\mathrm{g})+4 \mathrm{~F} .
$$

Adding the ionization potentials [16] of carbon $(11.26 \mathrm{ev})$ or of fluorine $(17.42 \mathrm{ev})$ gives 31.5 and $37.6 \mathrm{ev}$ for the energies required to form $\mathrm{C}^{+}$and $\mathrm{F}^{+}$ ions, respectively.

${ }^{2}$ Above $35 \mathrm{v}$ there are ions with high kinetic energy resulting from double ionization processes [20].
TABLE 2. Probable ionization processes for formation of atom ions

\begin{tabular}{|c|c|c|c|}
\hline Ion & $\begin{array}{c}\text { Appearance } \\
\text { potential }\end{array}$ & Ionization process & $\begin{array}{l}\text { Computed } \\
\text { threshold }\end{array}$ \\
\hline $\begin{array}{l}\mathrm{C}^{+} \\
\mathrm{F}^{+} \\
\mathrm{C}^{+} \\
\mathrm{F}^{+} \\
\mathrm{Cl}^{+} \\
\mathrm{F}^{-} \\
\mathrm{C}^{+} \\
\mathrm{F}^{+} \\
\mathrm{Br}^{+} \\
\mathrm{F}^{-} \\
\mathrm{C}^{+} \\
\mathrm{F}^{+} \\
\mathrm{I}^{+} \\
\mathrm{F}^{-} \\
\mathrm{F}^{-} \\
\mathrm{F}^{-} \\
\mathrm{Cl}^{-} \\
\mathrm{Cl}^{-} \\
\mathrm{F}^{-} \\
\mathrm{Br}^{-} \\
\mathrm{F}^{-} \\
\mathrm{I}^{-}\end{array}$ & $\begin{aligned} & \text { ev } \\
& 31.5 \pm 0.5 \\
& 36 \pm 1 \\
& 31 \pm 1 \\
& 31 \pm 1 \\
& 21 \pm 1 \\
& 20 \pm 1 \\
& 33 \pm 1 \\
& 29 \pm 1 \\
& 17.6 \pm 1 \\
& 17.9 \pm 1 \\
& 32.6 \pm 1 \\
& 33 \pm 1 \\
& 13.6 \pm 0.5 \\
& 14.0 \pm 1 \\
& \quad 4.5 \pm 0.3 \\
& 3.8 \pm 0.3 \\
& \approx 0 \\
& \quad 4.7 \pm 0.3 \\
& 3.5 \pm 0.3 \\
& \approx 0 \\
& 3.6 \pm 0.3 \\
& \approx 0\end{aligned}$ & $\begin{array}{l}\mathrm{CF}_{4} \rightarrow 4 \mathrm{~F}+\mathrm{C}^{+}+\mathrm{KE} \\
\mathrm{CF}_{4} \rightarrow 3 \mathrm{~F}+\mathrm{C}+\mathrm{F}^{+}+\mathrm{KE}^{-} \\
\mathrm{CF}_{3} \mathrm{Cl} \rightarrow 3 \mathrm{~F}+\mathrm{Cl}+\mathrm{C}^{+}+\mathrm{KE}^{-} \\
\mathrm{CF}_{3} \mathrm{Cl} \rightarrow \mathrm{CF}+\mathrm{F}+\mathrm{Cl}+\mathrm{F}^{+} \\
\mathrm{CF}_{3} \mathrm{Cl} \rightarrow \mathrm{CF}_{2}+\mathrm{F}^{-}+\mathrm{Cl}^{+}+\mathrm{KE}^{-} \\
\mathrm{CF}_{3} \mathrm{Br} \rightarrow 3 \mathrm{~F}+\mathrm{Br}+\mathrm{C}^{+} \\
\mathrm{CF}_{3} \mathrm{Br} \rightarrow \mathrm{CF}+\mathrm{F}+\mathrm{Br}^{+} \mathrm{F}^{+} \\
\mathrm{CF}_{3} \mathrm{Br} \rightarrow \mathrm{CF}_{2}+\mathrm{Br}^{+}+\mathrm{F}^{-}+\mathrm{KE}^{+} \\
\mathrm{CF}_{3} \mathrm{I} \rightarrow 3 \mathrm{~F}+\mathrm{I}+\mathrm{C}^{+} \\
\mathrm{CF}_{3} \mathrm{I} \rightarrow 2 \mathrm{~F}+\mathrm{I}+\mathrm{C}+\mathrm{F}^{+} \\
\mathrm{CF}_{3} \mathrm{I} \rightarrow \mathrm{CF}_{2}+\mathrm{I}^{+}+\mathrm{F}^{-}+\mathrm{KE} \\
\mathrm{CF}_{4} \rightarrow \mathrm{CF}_{3}+\mathrm{F}^{-} \\
\mathrm{CF}_{3} \mathrm{Cl} \rightarrow \mathrm{CF}_{2} \mathrm{Cl}+\mathrm{F}^{-} \\
\mathrm{CF}_{3} \mathrm{Cl} \rightarrow \mathrm{CF}_{3}+\mathrm{Cl}^{-} \\
\mathrm{CF}_{3} \mathrm{Cl} \rightarrow \mathrm{CF}_{2}+\mathrm{F}^{-} \mathrm{Cl}^{-} \\
\mathrm{CF}_{3} \mathrm{Br} \rightarrow \mathrm{CF}_{2} \mathrm{Br}^{-} \mathrm{F}^{-} \\
\mathrm{CF}_{3} \mathrm{Br} \rightarrow \mathrm{CF}_{3}+\mathrm{Br}^{-} \\
\mathrm{CF}_{3} \mathrm{I} \rightarrow \mathrm{CF}_{2} \mathrm{I}^{-} \mathrm{F}^{-} \\
\mathrm{CF}_{3} \mathrm{I} \rightarrow \mathrm{CF}_{3}+\mathrm{I}^{-}\end{array}$ & 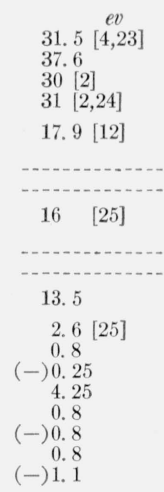 \\
\hline
\end{tabular}

Table 2 lists some observed appearance potentials from table 1 and ionization potentials computed from thermochemical data. The observed appearance potentials for both $\mathrm{C}^{+}$and $\mathrm{F}^{+}$of $\mathrm{CF}_{4}$ can be ascribed to a process involving complete atomization of the molecule. The heat of atomization of $\mathrm{CF}_{3} \mathrm{Cl}$ is also known and the appearance potential of $\mathrm{C}^{+}$is again consistent with a process involving complete atomization. The appearance potentials for the halogen ions are less than would be required for a process involving complete atomization. Table 2 lists processes that are consistent with the observed appearance potentials. The computed thresholds of column 4 include an estimate of $D(\mathrm{C}-\mathrm{F})=5.0 \mathrm{ev}$ derived from the $\mathrm{CF}$ band spectrum [24], and the upper bound to $D\left(\mathrm{CF}_{2}-\mathrm{F}\right)=5.0$ ev estimated by Rabinovitch and Reed [12]. These values and the above computed $D\left(\mathrm{CF}_{3}-\mathrm{F}\right)=6.2$ ev subtracted from the heat of atomization of $\mathrm{CF}_{4}(20.2 \mathrm{ev})$ gives an estimate of the lower limit of the bond-dissociation energy $D(\mathrm{CF}-\mathrm{F})=4 \mathrm{ev}$, or $92 \mathrm{kcal}$.

Heats of formation of $\mathrm{CF}_{3} \mathrm{Br}$ and $\mathrm{CF}_{3} \mathrm{I}$ have not been published, but the magnitudes of the appearance potentials of $\mathrm{C}^{+}$for these molecules indicate that complete atomization must be involved and presumably the products have high kinetic energy. The halogen ions from $\mathrm{CF}_{3} \mathrm{Br}$ appear at lower voltages and the interpretation is speculative. Production of $\mathrm{F}^{+}$from $\mathrm{CF}_{3} \mathrm{I}$ may involve complete atomization of the compound, but $\mathrm{I}^{+}$and $\mathrm{Br}^{+}$seem to come from ion-pair formation processes.

\subsection{Negative Ions}

Two negative ions formed by dissociative attachment are observed in the mass spectrum of $\mathrm{CF}_{4}$. The appearance potential of about $4.5 \mathrm{ev}$ for $\mathrm{F}^{-}$ added to the electron affinity of fluorine $3.6 \mathrm{ev}$, [26] gives an energy of $8.1 \mathrm{ev}$ available for dissociation. The above value of $D\left(\mathrm{CF}_{3}-\mathrm{F}\right)=6.2 \mathrm{ev}$ leaves $1.9 \mathrm{ev}$ excess energy. Presumably a similar process is involved in the formation of $\mathrm{CF}_{3}^{-}$, but in this case the electron affinity is unknown. 
In table 2, formation of $\mathrm{F}^{-}$by attachment is tentatively ascribed to the same process in all the compounds. In the chloride, bromide, and iodide the appearance potential is the same within experimental error, and this suggests that the same mechanism is involved. In all three cases there is a large excess energy of about $2.8 \mathrm{ev}$.

Simple dissociative electron attachment can also account for production of $\mathrm{Cl}^{-}, \mathrm{Br}^{-}$, and $\mathrm{I}^{-}$at 0 volts. In each case the electron affinity [25] is slightly greater than the bond-dissociation energy, and some excess energy is involved. In $\mathrm{CF}_{3} \mathrm{Cl}$ there is a second attachment process for $\mathrm{Cl}^{-}$at $4.7 \mathrm{ev}$, and this is ascribed to dissociation of $\mathrm{F}$ and $\mathrm{Cl}^{-}$from the molecule. This is in agreement with the upper bound, $D\left(\mathrm{CF}_{2}-\mathrm{F}\right)=5.0$ ev estimated by Rabinovitch and Reed [12].

In $\mathrm{CF}_{3} \mathrm{Cl}, \mathrm{F}^{-}$is formed by an ion-pair process at $20 \mathrm{ev}$. There are two positive ion processes that fall near this, and the explanation of the ion pair process is uncertain. In $\mathrm{CF}_{3} \mathrm{Br}$ and $\mathrm{CF}_{3} \mathrm{I}$ the ionpair process seems to be formation of $\mathrm{Br}^{+}$or $\mathrm{I}^{+}$ and $\mathrm{F}^{-}$, and the observed appearance potentials are consistent with the computed thresholds.

\section{Summary}

The appearance potentials of $\mathrm{CF}_{3}{ }^{+}$can be accurately accounted for by assuming that the ionization potential of $\mathrm{CF}_{3}$ is $9.3 \mathrm{ev}$. The appearance potentials of most of the positive and negative ions are tentatively ascribed to processes listed in column 3 of table 2. In general, there is excess kinetic energy associated with formation of atom ions and this combined with the experimental errors leaves a margin of uncertainty in identifying the ionization processes. Although data for computing the thresholds for appearance of $\mathrm{C}^{+}$and $\mathrm{F}^{+}$from the bromide and iodide are not available, it is safe to predict they are below the observed appearance potentials for the processes postulated. There is no basis for computing appearance potentials of polyatomic fragment ions other than $\mathrm{CF}_{3}$ because the ionization potentials of these fragments are unknown.
The authors are indebted to C. E. Berry of Consolidated Electrodynamics Corp. for detailed discussion and original experimental data on the measurement of kinetic energies using the beamdeflection technique, and to Morris Krauss for helpful discussions.

\section{References}

[1] Fluorine chemistry, vol II, p. 347 (J. H. Simons, ed., Academic Press, Inc., New York, N. Y., 1954).

[2] F. W. Kirkbride and F. G. Davidson, Nature 174, 79 (1954).

[3] D. W. Scott, W. D. Good, and G. Waddington, J. Am. Chem. Soc. $7 \%, 242$ (1955).

[4] R. S. Jessup, R. E. McCoskey, and R. A. Nelson, J. Am. Chem. Soc. $7 \%, 244$ (1955).

[5] N. W. Luft, J. Chem. Phys. 23, 973 (1955).

[6] V. H. Dibeler and F. L. Mohler, J. Research NBS 40, 25 (1948) RP1853.

[7] J. W. Warren and J. D. Craggs, Mass spectrometry, p. 36 (The Institute of Petroleum, London, 1952).

[8] J. Marriott and J. D. Craggs, Applied mass spectrometry, p. 173 (The Institute of Petroleum, London, 1954).

[9] J. D. Craggs and C. A. McDowell, Repts. Progr. Phys. 18, 375 (1955).

[10] V. H. Dibeler, R. M. Reese, and F. L. Mohler, J. Chem. Phys. 20, 761 (1952).

[11] J. B. Farmer, I. H. S. Henderson, F. P. Lossing, and D. G. H. Marsden, J. Chem. Phys. 24, 348 (1956).

[12] B. S. Rabinovitch and J. F. Reed, J. Chem. Phys. 22, 2092 (1954).

[13] V. H. Dibeler and R. M. Reese, J. Research NBS 54, 127 (1955) RP2573.

[14] H. D. Hagstrum, Rev. Mod. Phys. 23, 185 (1951).

[15] C. E. Berry, Phys. Rev. 78, 597 (1950).

[16] C. E. Moore, NBS Circular 467 (1949).

[17] W. M. Hickam and R. E. Fox, Phys. Rev. 98, 557A (1955).

[18] C. A. McDowell and D. C. Frost, J. Chem. Phys. 24, 173 (1956).

[19] A. H. Sehon and M. Szware, Proc. Roy. Soc. (London) [A] 209, 110 (1951).

[20] F. L. Mohler, V. H. Dibeler, and R. M. Reese, J. Chem. Phys. 22, 394 (1954).

[21] J. R. Dacey and J. W. Hodgins, Can. J. Research [B] 28, $193(1950)$.

[22] A. S. Carson, K. Hartley, and H. A. Skinner, Proc. Roy. Soc. (London) [A] 195, 500 (1949).

[23] R. N. Doescher, J. Chem. Phys. 20, 330 (1952).

[24] E. B. Andrews and R. F. Barrow, Proc. Roy. Soc. (London [A] 64, 481 (1951).

[25] H. O. Pritchard, Chem. Revs. 52, 529 (1953).

Washington, April 3, 1956. 